\title{
Selfishness among healthcare workers and nosocomial infections: a causal relationship?
}

\author{
Fernando Bellissimo-Rodrigues ${ }^{[1],[2], W a n e s s a}$ Teixeira Bellissimo-Rodrigues ${ }^{[1]}$ \\ and Mayra Gonçalves Menegueti ${ }^{[2]}$
}

[1]. Departamento de Medicina Social, Faculdade de Medicina de Ribeirão Preto, Universidade de São Paulo, Ribeirão Preto, SP. [2]. Comissão de Controle de Infecção Hospitalar, Hospital das Clínicas da Faculdade de Medicina de Ribeirão Preto, Universidade de São Paulo, Ribeirão Preto, SP.

Hand hygiene remains the single most important measure that can be undertaken by healthcare workers to prevent nosocomial infections. It has been 167 years since the pioneering study by Semmelweiss proved it effective ${ }^{1}$, and with the recent spread of multidrug-resistant bacteria in hospitals, hand hygiene is now more important than ever ${ }^{2}$. Despite being simple, effective, safe, and cheap, the worldwide compliance of healthcare workers to proper hand hygiene is typically below $50 \%$, and it is estimated that $50-70 \%$ of nosocomial infections are transmitted on the hands of healthcare workers ${ }^{3}$.

In the literature, innumerable reasons have been proposed to explain this fact, with a consensus that causes in the clinical setting are lack of resources, training, or supervision. However, even when dealing with highly skilled healthcare workers working in high-resource hospitals, full compliance with hand hygiene procedures has never been achieved ${ }^{3}$. Thus, we believe that, besides lack of resources and training, a low level of commitment to patient wellbeing is a major cause of low compliance.

When considering this hypothesis, it is important to analyze individual compliance with each of the 5 moments proposed by the World Health Organization (WHO) as critical points in hand hygiene protocols ${ }^{3}$. These moments are: 1) before touching a patient, 2) before aseptic/clean procedure, 3) after body fluid exposure, 4) after touching a patient, and 5) after touching the patient's surroundings. When the references cited by $W H O$ Guidelines on Hand Hygiene in Health Care are considered, and compliance analyzed at the pre- and post-care points, compliance at the post-care points is greater than compliance at the pre-care in $10(83.3 \%)$ of the 12 studies cited ${ }^{3}$.

As well, the general lack of commitment to patient wellbeing commonly observed in hospitals is supported by the compliance with different isolation precautions recommended by the Centers for Disease Control and Prevention (CDC) $)^{4}$. While compliance with contact precautions usually falls below $30 \%{ }^{5}$, compliance with respiratory precautions in our hospital is almost $100 \%$ (data not published). We believe that the main explanation for this observation is the perception among healthcare workers

Address to: Dr. Fernando Bellissimo-Rodrigues. Dept ${ }^{\circ}$ de Medicina Social/HC/ FMRP/USP. Av. Bandeirantes 3900/2 andar, Bairro Monte Alegre, 14048-900 Ribeirão Preto, SP, Brasil.

Phone: 55 16 3602-2714; Fax: 5516 3602-1562

e-mail: fbellissimo@fmrp.usp.br

Received 14 August 2014

Accepted 19 August 2014 that tuberculosis and meningococcal meningitis pose a real risk to themselves ${ }^{6}$, while infections caused by multidrug-resistant pathogens, such as Klebsiella pneumoniae, Pseudomonas aeruginosa, or Acinetobacter baummanni, typically spread to only the hospitalized patients?

If we are correct, infection control in hospitals must include efforts to motivate a strong commitment from all healthcare workers to the main objective of their work: promoting the patient's health. In the past, this has been partially accomplished by multimodal hand hygiene campaigns, which have tried to improve compliance through behavioral science methods, including motivational lectures and posters ${ }^{3,8}$. In our hospital, we have used a technique of motivating healthcare workers by asking them to put themselves in the place of the patient, and consider how they would like to be cared for if they were the patient. This technique may be easily used during clinical rounds and lectures, or as a wall reminder, as shown in Figure 1. When this technique is successful, a marked change in behavior is observed among the target healthcare workers, as they realize that someday it may be their turn to be the patient. Thus, we should all ask ourselves: am I caring for my patients as I would want to be cared for?

It could be you in this bed...

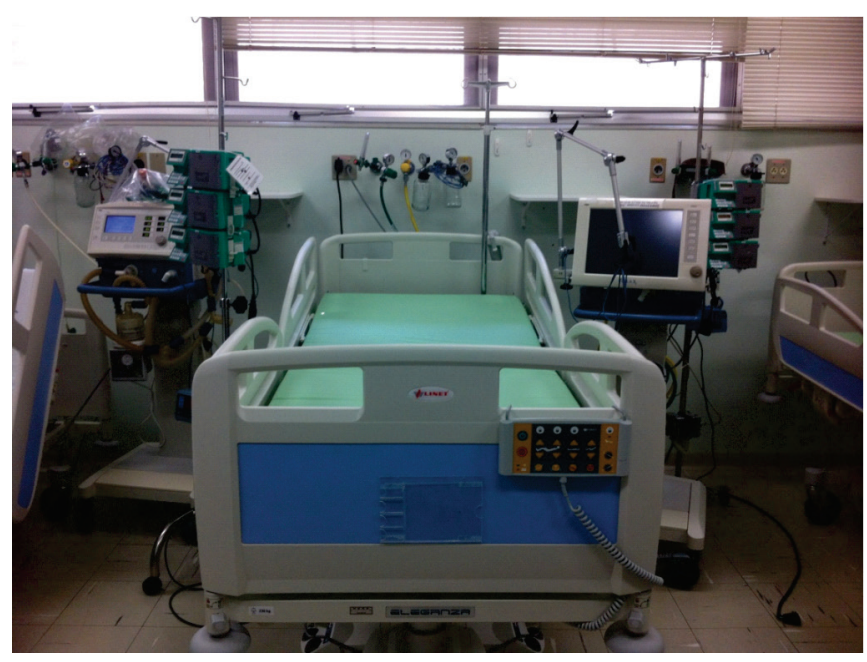

...so, give the patients the same care you would like to have, perform hand hygiene before touching them!

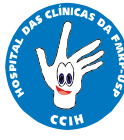

FIGURE 1 - Wall reminder promoting hand hygiene procedure. 


\section{CONFLICT OF INTEREST}

The authors declare that there is no conflict of interest.

\section{REFERENCES}

1. Semmelweis IP. The etiology, concept, and prophylaxis of childbed fever, translated by K. Codell Carter. Madison: The University of Wisconsin Press; 1983.

2. Rabelo MA, Bezerra Neto AM, Loibman SO, Lima JLC, Ferreira EL, Leal NC, et al. The occurrence and dissemination of methicillin and vancomycin-resistant Staphylococcus in samples from patients and health professionals of a university hospital in Recife, State of Pernambuco. Rev Soc Bras Med Trop 2014; 47:437-446.

3. World Health Organization (WHO). WHO guidelines on hand hygiene in health care, 2009. [Cited 2014 June 14]. Available at: http://www.who. int/gpsc/5may/tools/9789241597906/en/.
4. Centers for Disease Control and Prevention (CDC). 2007 guideline for isolation precautions: Preventing transmission of infectious agents in healthcare settings. [Cited 2014 June 14]. Available at http://www.cdc. gov/hicpac/pdf/isolation/Isolation2007.pdf.

5. Dhar S, Marchaim D, Tansek R, Chopra T, Yousuf A, Bhargava A, et al. Contact precautions: More is not necessarily better. Infect Control Hosp Epidemiol 2014; 35:213-221.

6. Pazin-Filho A, Soares CS, Ferrais AS, Oliveira e Castro PT, BellissimoRodrigues F, Nogueira JA, et al. Tuberculosis among health care workers in a Brazilian tertiary hospital emergency unit. Am J Emerg Med 2008; 26:796-798

7. Bellissimo-Rodrigues F, Gomes AC, Passos AD, Achcar JA, Perdoná GS, Martinez R. Clinical outcome and risk factors related to extendedspectrum beta-lactamase-producing Klebsiella spp. infection among hospitalized patients. Mem Inst Oswaldo Cruz 2006; 101:415-421.

8. Allegranzi B, Gayet-Ageron A, Damani N. Global implementation of WHO's multimodal strategy for improvement of hand hygiene: a quasiexperimental study. Lancet Infect Dis 2013; 13:843-851. 